\title{
Uma agenda científica para a eugenia latina?
}

\section{A scientific agenda for Latin eugenics?}

\author{
Ana Carolina Vimieiro-Gomes \\ Professora, Departamento de História/Universidade Federal de Minas Gerais. \\ carolvimieiro@ufmg.br
}

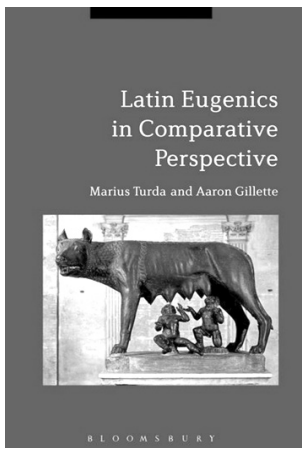

TURDA, Marius; GILLETTE, Aaron. Latin eugenics in comparative perspective. London: Bloomsburry. 2014. 320p.

$\mathrm{A}$ obra Latin eugenics in comparative perspective, publicada por Marius Turda e Aaron Gillette em 2014, é uma audaciosa contribuição para a história dos conceitos e práticas do movimento eugênico em perspectiva transnacional. Diante de um tema bastante explorado pela historiografia, o diferencial desse livro está justamente em tomar como objeto a "Eugenia Latina, reinterpretando essa categoria polêmica e ainda pouco explorada". Para tal empreitada, os autores propõem uma abordagem comparativa envolvendo os sentidos e usos científicos, culturais e políticos da eugenia desenvolvidos em alguns contextos locais europeus e latino-americanos. Entretanto, o livro busca explorar as idiossincrasias da dimensão intraeuropeia da eugenia latina, mobilizando como ponto de diálogo a ideia de uma eugenia "latinizada" na América Latina - antes desenvolvida por Nancy Stepan (2005) em A hora da eugenia - mas propondo avançá-la.

Latin eugenics in comparative perspective é estruturado em sete capítulos, com a conclusão seguida de um epílogo. Essa estruturação segue organizada segundo duas dimensões: temporal, com capítulos que tratam da eugenia em fins do século XIX, no entreguerras e no pós-guerra; e temática, em que são debatidas as especificidades da eugenia latina no que diz respeito à esterilização, à religião, ao racismo científico e à sua comunidade de praticantes, com a criação de uma Federação de Sociedades da Eugenia Latina, nos anos 1930. Aliás, os autores dedicam capítulos separados para a eugenia latina intraeuropeia e a eugenia na América Latina, de forma a pôr em evidência as aproximações e as diferenciações dos movimentos eugênicos nessas duas regiões. Dentre esse conjunto narrativo, destaca-se a interpretação sobre a eugenia no período entreguerras, momento em que, para os autores, as especificidades da agenda científica da eugenia latina se afirmaram e consolidaram no cenário científico internacional. Salta aos olhos a tentativa de mobilizar uma variedade de fontes primárias e o esforço de síntese dos autores, buscando, por meio de revisão bibliográfica, percorrer o debate sobre a história da eugenia em diversos contextos nacionais. 
Afinal, como Turda e Gillette caracterizam a eugenia latina? O que diferenciaria sua agenda científica da de outros movimentos eugênicos?

Os autores abrem o livro com a afirmação de que a eugenia latina seria um dos ramos da eugenia que acabou por conformar um conjunto de ideias e práticas adotadas por muitos eugenistas europeus, que consideravam seus países pertencentes a uma comunidade cultural latina, de abrangência internacional. Os países considerados latinos que são tratados no livro são: França, Itália, Espanha, Bélgica, Portugal e Romênia, na Europa; Argentina, México, Cuba, Brasil e Peru, na América Latina. Essa cultura latina seria baseada na concepção de panlatinismo: uma tradição inventada desde fins do século XIX e supostamente partilhada pelos países latinos - definida principalmente em termos histórico-genealógicos (herança romana), por aspectos culturais e linguísticos partilhados e por concepções religiosas comuns (catolicismo). A partir desse pano de fundo, tentam demonstrar que existiu dentro do movimento eugênico latino europeu certo compromisso com essa latinidade, embora os eugenistas de cada país tivessem buscado criar e desenvolver sua própria eugenia nacional, segundo valores culturais e científicos locais próprios. Para Turda e Gillette, o caráter distinto da eugenia latina estaria na crença no poder da ciência como meio de modernizar o Estadonação, ao mesmo tempo preservando alguns dos valores dessa tradição cultural.

Desse modo, para os autores de Latin eugenics in comparative perspective, esses valores culturais orientaram as particularidades da agenda científica da eugenia latina e, assim, os fundamentos de oposição à eugenia nórdica e anglo-saxã. Nessa direção, um dos argumentos dos autores é o de que a eugenia latina, no entreguerras, mas principalmente nos anos 1930, desenvolveu-se em um conjunto coerente de ideias sociais, biológicas e culturais dirigidas mais às noções de indivíduo e de comunidade nacional, e menos à ideia de classe e de raça, enfatizada pela eugenia nórdica e anglo-saxã. Em jogo nessa perspectiva estavam tentativas de atingir os contornos sociais e [bio]políticos para o "Estado de bem-estar moderno". Na agenda científica da latina, diferente da vertente anglo-saxã e nórdica, buscava-se a melhoria biológica do indivíduo e do coletivo por meio da medicina preventiva, da higiene social, dos estudos demográficos e da saúde pública, em vez da engenharia genética, da seleção racial e esterilização compulsória. A eugenia latina tinha, então, como principais fundamentos intelectuais o neolamarckismo, a puericultura, a biotipologia e a homicultura. A faceta política dessa eugenia expressou-se na sua mobilização pelos nacionalismos e pelo fascismo e até mesmo na aproximação com o catolicismo, como na Itália. Tais argumentações são demonstradas no livro por meio da revisão bibliográfica e pela empiria, a partir dos discursos e práticas dos cientistas e de instituições eugenistas tais como sociedades, revistas médicocientíficas e organizações governamentais e políticas dos vários países privilegiados na análise. Indícios, conforme destacado pelos autores, de uma diacrônica e efetiva influência do pensamento da eugenia latina desde fins dos Oitocentos. Mesmo com risco de conduzir o leitor à simplificação e à superficialidade interpretativas comuns a esse tipo de recorte abrangente envolvendo vários cenários, o livro apresenta problematizações renovadas e várias evidências empíricas de conexões entre países, da circulação internacional e das apropriações locais desse modelo de eugenia latina, que foram pouco exploradas e merecem ser mais bem estudadas. 
A obra termina com uma observação instigante sobre o pós-guerra. Os autores levamnos a interpretar a eugenia latina como empreendimento bem-sucedido, ao afirmar que vários elementos da sua agenda científica acabaram por sobreviver aos ataques políticos e acadêmicos à eugenia depois dos anos 1950, deflagrados pelas trágicas consequências das políticas eugênicas da Segunda Guerra Mundial. Menos associados ao nazismo e às concepções racialistas e racistas radicais, argumentam os autores, os fundamentos intelectuais da eugenia latina necessitaram de poucas mudanças para se acomodar à nova cultura política do pós-guerra. A reformulação da eugenia nesse novo contexto inspira estudos críticos e aprofundados sobre o tema, o que torna Latin eugenics in comparative perspective leitura importante para os pesquisadores que se interessam pela história das variadas propostas de intervenção nas sociedades modernas a partir de teorias biológicas visando ao suposto progresso da humanidade.

\section{REFERÊNCIA}

STEPAN, Nancy Leys.

A hora da eugenia: raça, gênero e nação na

América Latina. Rio de Janeiro: Editora Fiocruz.

2005. 